\title{
Uma abordagem interdisciplinar na prática educativa em educação profissional e tecnológica
}

\author{
Carlos Emilio Padilla Severo - carlossevero@ifsul.edu.br - DEPEX/IFSul
}

\begin{abstract}
Resumo. Este trabalho apresenta os resultados de uma abordagem interdisciplinar na educação profissional. Com base em uma prática educativa a qual envolveu um estudo de caso acerca da influência de projetos de extensão na formação e aprendizagem de estudantes do ensino tecnológico. Os resultados demonstram os aspectos positivos da vivência prático-profissional dos estudantes.
\end{abstract}

Palavras-chave. interdisciplinaridade; extensão acadêmica; aprendizagem.

\section{An interdisciplinary approach about educational practice in professional and technological education}

\begin{abstract}
This paper shown the results about an interdisciplinary approach in the professional education. The educational practice involved a case study about the influence of extension projects in the education and learning of students of technical education. The results show the positive aspects of practical and professional experience of the students.
\end{abstract}

Keywords. Interdisciplinarity; academic extension projects; learning.

\section{Introdução}

Neste trabalho, abordamos e viabilizamos uma prática educativa visando a promoção da interdisciplinaridade na educação profissional e tecnológica. Para isso, apresentamos os resultados de uma investigação pautada na ampliação de oportunidades para desenvolvimento da aprendizagem de estudantes do curso de tecnologia em Análise e Desenvolvimento de Sistemas do Instituto Federal Sul-rio-grandense (IFSul).

Esta proposta educativa foi motivada pela superação de fatores que limitam o desenvolvimento da aprendizagem no espaço de uma aula tradicional. Entre esses fatores, elencamos: o espaço e tempo destinado a aula; bem como, a estrutura curricular do curso em combinação com as ementas dos componentes curriculares. Tais fatores instigaram a reflexão acerca de possibilidades de diversificação de oportunidades de aprendizagem ao estudante. Dessa forma, propomos uma prática educativa promovendo a ampliação de espaços educativos, onde o estudante tenha oportunidade de maior interação com docentes e entre seus pares.

Sendo assim, levantamos as seguintes questões de pesquisa para auxílio na 
delimitação do estudo e definição dos objetivos da investigação, são elas: como ampliar espaços de aprendizagem fora do escopo da sala de aula tradicional? Quais alternativas permitem a interdisciplinaridade na abordagem pedagógica? De que forma uma prática pedagógica visando a interdisciplinaridade influencia na aprendizagem dos estudantes?

Para tentarmos resolver nossa questão de pesquisa propomos o desenvolvimento de um projeto de ensino envolvendo a elaboração de um software. Desde a etapa de levantamento de requisitos, passando pela modelagem conceitual e culminando na codificação do produto final. Trata-se de um laboratório de experimentação prática, onde o estudante pode vivenciar aspectos relacionados à prática profissional ainda no interior da escola.

O objetivo geral do trabalho foi possibilitar uma alternativa às aulas teóricopráticas curriculares do curso superior de Tecnologia em Análise e Desenvolvimento de Sistemas, na forma de realização de uma prática interdisciplinar. Em tal prática interdisciplinar os estudantes encontraram desafios os quais despertaram a reflexão acerca das melhores soluções para problemas encontrados nas suas futuras atividades profissionais. A partir da definição do objetivo geral, elencamos os seguintes objetivos específicos: permitir aos estudantes uma ampliação de seus espaços de aprendizagem; apresentar uma proposta para potencialização da mediação pedagógica; possibilitar a utilização e combinação de tecnologias e ferramentas no processo de desenvolvimento de software; e, enfatizar a importância das relações no trabalho em equipe.

Para fundamentação da proposta educativa anunciada neste texto, buscamos subsídios teóricos na literatura sobre alguns aspectos relevantes para investigação os quais são apresentados nas próximas sessões.

\section{Os limites da aula tradicional}

Iniciamos a exposição de nossa base teórica a partir de reflexões acerca dos limites impostos pela sala de aula tradicional na aprendizagem do estudante. Portanto, concordamos com Pacheco (2010), explanando que a educação não ocorre apenas nos espaços de educação formal. Ela resulta das experiências vivenciadas em todos os espaços da sociedade.

Assim, entendemos que a interação entre escola e comunidade pode ser explorada para fins educativos e oportunizar espaços onde o estudante possa vivenciar a realidade de suas futuras práticas profissionais. Seja ela uma educação formal ou não.

Em relação a formalidade ou não da educação, Libâneo (2010) prefere a referência ao termo intencionalidade da educação. Quando não há intencionalidade no ato educativo o autor utiliza o termo educação informal. Já, quando ocorre uma ação intencional, que é o caso da educação escolar, os termos utilizados são: educação formal ou não-formal. De acordo com o autor, a intencionalidade está relacionada ao planejamento e sistematização prévia da proposta educativa. Todavia, Gadotti (2009) argumenta que não há educação sem intencionalidade. Esta ocorre em qualquer modalidade de educação. O que pode ser em maior ou menor grau de formalidade atuando sobre o processo educativo.

Neste trabalho, consideramos a realização de uma prática pedagógica que vise explorar o potencial do espaço de educação não-formal. Ou seja, aquele que propicia o desenvolvimento da aprendizagem do estudante fora do espaço-tempo da sala de aula tradicional. Pois, assim entendemos que o espaço-tempo disponível para o 
desenvolvimento de atividades previstas nos planos de aula do professor, muitas vezes não são apropriados para a atividade pedagógica desejada. O que limita a capacidade de mediação pedagógica docente. Souza et al (2010), destacam que a maior parte do tempo de uma aula é gasto com a exposição de conteúdo do professor, pouco tempo é destinado à mediação. Além disso, em algumas situações a organização do espaço físico da sala de aula limita as atividades que poderiam ser propostas. O que depende da proposta pedagógica planejada pelo docente e a dinâmica das atividades que serão realizadas pelos estudantes.

Outro fator que entendemos cercear a prática pedagógica docente e, consequentemente, reduzir condições para favorecimento do desenvolvimento da aprendizagem do estudante é o limite imposto pelo currículo. Embora Sacristán (2013) esclareça que o currículo pode assumir diversas definições no cotidiano escolar, nosso interesse está na sua utilização como instrumento para estruturação dos conteúdos de um curso. Neste caminho, o autor destaca que o currículo é utilizado para constituição da carreira do estudante, onde os conceitos abordados ao longo do percurso formativo são organizados em uma sequência de conteúdos de aprendizagem. Entretanto, o autor informa que currículo também significa território demarcado e regrado, onde os professores devem seguir um plano de conteúdos imposto. Isso reforça nossa convicção de que o currículo de um curso tende a compartimentalizar conteúdos através de distintos componentes curriculares, impondo fronteiras e poucas possibilidades de integração de conteúdos. Isso, dado o tempo de integralização dos conteúdos para cada componente curricular.

Demo (2007) apresenta o conceito de currículo intensivo o qual seria uma alternativa ao modelo didático de aula organizada pela exposição de pedaços estanques de conteúdos. Pedaços esses desconexos, onde, muitas vezes, os temas não são relacionados uns com os outros. Fato que enaltece a mera transmissão de conteúdos. $\mathrm{O}$ currículo intensivo privilegia a educação pela pesquisa onde o princípio é o questionamento reconstrutivo entre professor e aluno. Com isso, buscando-se superar o paradigma de professor que somente ensina e estudante que apenas aprende. O currículo intensivo implica no aprofundamento do tema em estudo em longo prazo. Geralmente, além do limite de tempo da aula. O que, no nosso ponto de vista, pode propiciar uma constante interação dialógica entre os estudantes e estudantes com professor. E, que pode culminar em uma mediação pedagógica mais rica.

O foco da estratégia pedagógica baseada no currículo intensivo está na interdisciplinaridade. Esta é outra base teórica que fundamenta nosso trabalho de pesquisa e a qual é apresentada na próxima seção.

\section{Interdisciplinaridade na educação profissional e tecnológica}

De acordo com Moura (2008) o mundo do trabalho e sociedade em geral, necessita de profissionais com discernimento para enfrentarrm problemas, antecipando soluções através de estratégias de geração de conteúdo. Isso tudo, com capacidade de autonomia para que possam atuar em uma perspectiva de transformação social. Gadotti (2009), complementa nos esclarecendo que as transformações tecnológicas, políticas e econômicas atingem diretamente o mundo do trabalho. $O$ que exige constante capacitação do estudante para inserção no mercado de trabalho. Portanto, apostamos na interdisciplinaridade como mecanismo para concepção de uma abordagem pedagógica que contemple possibilidades de capacitação do estudante as quais busquem contornar 
os limites impostos pela aula tradicional.

Gadotti (2009) conceitua interdisciplinaridade como um enfoque teóricometodológico na educação o qual visa contornar os problemas associados a compartimentalização de saberes. Segundo o autor, a interdisciplinaridade surge como um mecanismo que visa romper com a hiperespecialização e fragmentação de conhecimentos através da integração das ciências. Thiesen (2008), acrescenta que no campo conceitual a interdisciplinaridade será sempre uma alternativa a abordagem disciplinar normalizadora. Ou seja, trata-se de uma abordagem que visa uma alternativa ao modelo de educação baseada em parcelas de conhecimento.

Entretanto, de acordo com Luck (2001), atividades interdisciplinares tendem a uma sobrecarga de trabalho o que gera receio nos professores envolvidos em errar, ou até mesmo falta de motivação em romper com hábitos e acomodações ao longo da experiência pedagógica. Por outro lado, Demo (2007) nos motiva na prática pedagógica inovadora esclarecendo que projetos interdisciplinares são importantes no processo de ensino e aprendizagem quando envolvem a pesquisa como um princípio educativo. Por fim, recorremos a Freire (1987), ressaltando que interdisciplinaridade é um processo metodológico de construção do conhecimento pelo sujeito em sua relação com sua realidade e cultura. Portanto, reforçamos a importância de uma abordagem pedagógica baseada na interdisciplinaridade na educação profissional e tecnológica.

Assim, buscamos na literatura investigações acerca da interdisciplinaridade no ensino e aprendizagem relacionadas a nossa proposta. Encontramos muitos trabalhos nesta temática. Mas, nosso interesse está nas investigações acerca da interdisciplinaridade em cursos relacionados a Computação/Informática. Nesta linha, o trabalho de França et al (2014) apresenta um relato de experiência acerca da adoção de uma metodologia de ensino e aprendizagem dos componentes curriculares do ensino fundamental com base no pensamento computacional. Os autores destacam a aplicabilidade dos conceitos da computação no ensino de temas relacionados a Matemática, Química, Biologia, Educação Física, Artes, Língua Portuguesa e Redação. Já Cardoso e Antonello (2015), apresentam os resultados de uma prática pedagógica interdisciplinar no ensino de lógica de programação para estudantes dos anos iniciais de um curso superior em Sistemas de Informação. Os autores articularam a integração de dois componentes curriculares do curso e através de dinâmicas e uso de ferramentas de programação. Com isso, obtiveram resultados positivos na aprendizagem dos estudantes. No trabalho de Oliveira (2013) encontramos algumas implicações acerca da utilização de jogos sérios no ensino e aprendizagem. Neste caso, os autores apresentam o projeto de um jogo para auxílio na aprendizagem de conceitos e práticas envolvidas na gestão de riscos no processo de desenvolvimento de software. Enquanto que Cordenonzi et al (2015) apresentam reflexões acerca de uma investigação sobre a construção de objetos de aprendizagem a partir da relação interdisciplinar da Matemática e Programação de Computadores. O trabalho visou a atenuação dos índices de reprovação dos estudantes nas disciplinas.

Portanto, podemos observar que há uma grande preocupação com a melhoria de práticas educativas na educação profissional e tecnológica que visem melhorar o desempenho dos estudantes ao longo de suas formações acadêmicas. Além disso, o esforço nas pesquisas também visa evitar a evasão de estudantes, tentando garantir a 
permanência através do êxito no desenvolvimento do conhecimento dos estudantes. Sendo assim, este trabalho apresenta uma proposta interdisciplinar que tenta ampliar oportunidades, vivências e práticas, na expectativa de melhores condições para o desenvolvimento de aprendizagem dos estudantes. A próxima sessão apresenta a abordagem metodológica empregada no trabalho investigativo.

\section{Abordagem metodológica da prática educativa}

Nossa proposta investigativa tem como base uma pesquisa de natureza qualitativa, visto que estamos interessados em refletir e avaliar um processo educativo pautado em uma prática pedagógica interdisciplinar. O que corrobora com Sampieri et al (2013), os quais informam que o foco da pesquisa qualitativa está na compreensão de fenômenos. A partir do envolvimento dos participantes em um ambiente natural que permita o aprofundamento de experiências e significados. O que é o mais adequado para nossa proposta, visto que pretendemos avaliar a prática pedagógica interdisciplinar e sua influência na mediação docente. A ênfase investigativa está na pesquisa-ação com base em um estudo de caso, pois exploramos a construção do conhecimento por meio da prática. Para Tripp (2005), a pesquisa-ação é apropriada na resolução de problemas cotidianos na busca de informações que auxiliem na tomada de decisões sobre processos. Portanto, entendemos que esta é a abordagem apropriada para nossa pesquisa.

Nossa abordagem foi desenhada a partir de um projeto de extensão em parceria com uma instituição municipal de ensino fundamental. A instituição parceira demandou o desenvolvimento de um software de gestão de conteúdos educacionais. Nesta parceria, vimos uma oportunidade de realização de um trabalho interdisciplinar, onde os estudantes pudessem vivenciar a realidade do processo de desenvolvimento de software. Além do que é trabalhado nas aulas teórico-práticas.

A proposta envolveu a participação de um estudante bolsista e outro voluntário, ambos vinculados ao curso superior de Tecnologia em Análise e Desenvolvimento de Sistemas do Instituto Federal Sul-rio-grandense (IFSul), campus Bagé. Cabe ressaltar, que o trabalho foi interdisciplinar, pois envolveu três professores de disciplinas distintas, mas inter-relacionadas da área de Informática do campus. Cujos conteúdos abordados ao longo do semestre convergiram na aplicação deste projeto. As disciplinas envolvidas foram: Modelagem de Sistemas de Informação, Banco de Dados e Programação para Internet. O estudo de caso envolveu a análise e levantamento de requisitos, bem como, a elaboração de uma aplicação de software para Internet. Para isso, o projeto foi desenvolvido em etapas.

A primeira etapa envolveu a definição da equipe de trabalho. A equipe executora foi constituída de um coordenador, dois professores colaboradores do próprio IFSul e um professor colaborador externo, ligado a instituição parceira que gerou a demanda do projeto. Para complementar a equipe de trabalho foi realizada a seleção do estudante bolsista e voluntário.

A segunda etapa abordou a análise dos requisitos e definição das funções desejadas do software. Esta etapa foi desenvolvida com colaboração dos docentes envolvidos no projeto de extensão. Um conjunto de documentos do software foi o produto resultante desta etapa. Tais como: diagramas de casos de uso e diagramas de 
classes. Os documentos foram produzidos pelos estudantes participantes do projeto.

$\mathrm{Na}$ terceira etapa, foi realizada a definição de tecnologias empregadas no processo de especificação e construção da aplicação. Nesta etapa, foram analisadas as potencialidades e limitações de tecnologias na concepção do software. Toda equipe foi envolvida nesta etapa.

A quarta etapa gerou a prototipação da aplicação, testes e validação junto a instituição parceira. Nesta etapa, os docentes atuantes no projeto, junto com os estudantes, construíram um protótipo do software.

A quinta etapa foi a implantação da aplicação. Nesta etapa foi definido um servidor de hospedagem para implantação da aplicação. O acompanhamento técnico do processo foi realizado pela equipe executora. Por fim, a sexta e última etapa foi o treinamento da comunidade escolar.

As ações elencadas nas etapas do projeto foram desenvolvidas no período de agosto a dezembro do ano de 2015. Os laboratórios de Informática e salas de orientação do IFSul foram utilizados para orientações e desenvolvimento do software pelos estudantes e equipe envolvida no projeto, bem como, para reuniões com a equipe participante em salas do próprio IFSul e instituição parceira.

Nossa pesquisa-ação foi de enfoque prático, pois envolveu um estudo de práticas específicas no âmbito das atividades do profissional de Análise e Desenvolvimento de Sistemas. Portanto, foi necessário o envolvimento de toda a equipe na aprendizagem dos estudantes participantes do projeto. Como instrumentos de pesquisa foram utilizados:

- A observação participante do orientador e docentes durante todo o processo de desenvolvimento do software. Durante cada etapa do processo e no desenvolvimento das atividades elencadas, foram realizadas mediações pedagógicas onde pudemos observar a construção da aprendizagem dos estudantes.

- Registros e documentos gerados durante o processo de desenvolvimento do software, constituídos de: notas, documentos de requisitos, diagramas de casos de uso, diagramas de classe e diagramas entidade-relacionamento.

- Um questionário semiestruturado que foi aplicado aos estudantes no final do estudo de caso. O questionário coletou dados acerca da autoavaliação dos estudantes sobre os efeitos da prática pedagógica.

Uma triangulação dos dados obtidos pelos instrumentos de pesquisa adotados foi realizada a fim de obtermos distintos pontos de vista. Este aspecto foi importante para melhor entendermos a analisarmos os resultados obtidos ao final de nossa investigação.

\section{Análise e discussão dos resultados}

A seguir, passamos a descrever os resultados da prática educativa interdisciplinar. Neste relato, descrevemos as dificuldades encontradas pela equipe e as aprendizagens desenvolvidas ao longo do processo. Cabe destacar, que dada a natureza qualitativa da pesquisa, a coleta e análise de dados foi realizada durante o processo. Portanto, não há uma divisão temporal entre coleta e análise. Entendemos que desta forma reduzimos a 
perda de informações importantes para o delineamento dos resultados. Para organizar o relato, dividimos o mesmo em partes, de acordo com cada etapa da metodologia elencada anteriormente.

Na primeira etapa de atividades do projeto foi realizada a definição da equipe de trabalho. O docente externo, vinculado à escola parceira, foi coautor do projeto, visto que foi a escola parceira que gerou a demanda. Os estudantes envolvidos no projeto foram selecionados por edital, cujos requisitos foram: desempenho e disponibilidade para participação. Para compor a equipe de colaboradores, foram convidados mais dois docentes para auxiliarem na orientação do desenvolvimento do software. Visto que envolveu uma integração interdisciplinar entre subáreas da Informática, tais como: análise e modelagem, programação, definição do banco de dados e tecnologias envolvidas na elaboração do software. A integração destas subáreas permitiu aos estudantes participantes do projeto terem uma visão holística sobre o processo de desenvolvimento de um sistema de informação. Esta foi uma das vantagens da proposta deste trabalho. Dado que, muitas vezes, no decorrer das atividades curriculares desenvolvidas em cada disciplina ao longo dos semestres do curso, não é possível esta integração. Isso pode ser observado a partir da fala dos estudantes:

Aluno 1: "Professor, agora entendo por que é importante aquele papo sobre camadas do sistema".

Aluno 2: "Sim. Eu não conseguia entender essa divisão. Pra mim era desnecessária".

A segunda etapa do trabalho envolveu a análise dos requisitos do software. Entende-se por análise de requisitos a identificação das principais funções desejadas do software, ou seja, o objetivo do software. O que o mesmo irá realizar e de que forma o usuário poderá tirar proveito das funcionalidades providas pela aplicação. Nesta etapa, houve um envolvimento muito grande da equipe de docentes e o responsável pela instituição parceira. Foram realizadas duas reuniões com o docente da escola para levantamento dos requisitos do software. A etapa permitiu muita aprendizagem dos estudantes envolvidos, pois puderam vivenciar como ocorre na prática o levantamento de requisitos, através de entrevistas e apontamentos de funcionalidades desejadas de um software. Ao final, os estudantes puderam observar a importância da documentação do software (diagramas elaborados) na sincronização da equipe de trabalho. Esta vivência nos surpreendeu muito, pela maturidade desenvolvida pelos estudantes ao longo do processo. Vejamos alguns comentários dos estudantes:

Aluno1: "Como funciona atualmente o processo de registro das notas lá na escola?"

Aluno 1: “Sim, mas há alguma diferença entre o sistema de avaliação em cada série?"

Aluno 2: "Claro, as séries iniciais trabalham com conceito. Devemos pensar uma melhor estratégia para tratar isso."

$\mathrm{Na}$ terceira etapa do trabalho foram definidas as tecnologias empregadas na elaboração dos documentos de requisitos do software. Também foram definidas tecnologias empregadas na programação do sistema de gestão de conteúdos. Utilizamos para isso ferramentas para modelagem de diagramas. Esta foi outra etapa muito valiosa para aprendizagem dos estudantes, pois puderam visualizar e sentir as dificuldades 
encontradas por uma equipe de desenvolvimento de software. Dificuldades como transcrição do texto de requisitos em diagramas que representam o domínio de funções do software. Os estudantes aprenderam muito e aplicaram os conceitos abordados nas disciplinas do curso. A principal dificuldade encontrada nesta etapa foi a tradução da entrevista que levantou a descrição textual dos requisitos do sistema em diversos diagramas que constituíram a documentação do processo de desenvolvimento de software.

A terceira etapa permitiu que os alunos evidenciassem a importância e utilidade da linguagem UML na descrição dos modelos do sistema de informação. Isso, deve-se ao fato de que a linguagem possui construções apropriadas para descrição de cada fase de desenvolvimento de uma aplicação de software. Permitindo, até mesmo, a previsão de uma arquitetura do software proposto. O que ficou evidente para os estudantes os quais opinaram e realizaram reflexões sobre o melhor modelo de software a ser empregado. Esta foi uma experiência muito gratificante tanto para os estudantes como para a equipe de orientadores envolvida, visto que os estudantes puderam compreender a finalidade dos diagramas durante a especificação conceitual do software.

Aluno 1: "Nossa, este modelo não tem nada a ver com o nosso protótipo."

Aluno 2: "Claro, não tínhamos previsto esta funcionalidade do software."

Aluno1: "Temos que modificar nosso diagrama para atender este requisito então."

A quarta etapa do projeto envolveu a construção (programação) do software com a tecnologia escolhida. Em posse dos documentos de requisitos do software e de acordo com a arquitetura definida na etapa anterior, foi iniciado o processo de codificação da aplicação. Salientamos nossa satisfação com o desempenho dos estudantes no decorrer desta etapa. Esta foi a etapa onde pudemos observar a contribuição que um projeto de extensão como este pode oferecer para aprendizagem dos estudantes. $\mathrm{O}$ desenvolvimento de um software costuma ser muito complexo. Visto que envolve aspectos relacionados à lógica. Bem como, dificuldades encontradas pela própria linguagem de programação empregada. Isso ocorre dada a grande carga de abstração envolvida. Realmente, não é fácil para estudantes enfrentarem as dificuldades impostas pelo processo de codificação de um software. Entretanto, os estudantes participantes do projeto foram muito bem nesta etapa. Trabalharam com muita dedicação na elaboração do sistema de gestão de conteúdos para escola.

Durante a programação do sistema os estudantes puderam entender na prática conceitos como: abstração, herança e modularização no processo de programação de aplicações de software. Esta etapa proporcionou uma aprendizagem rica em diversos aspectos relacionados a construção de programas. Destacamos algumas falas:

Aluno 2: "Não, isso não pode ser codificado como herança."

Aluno 1: "Pode sim, pois um professor também pode ser aluno."

Aluno 2: "Não no caso lá da escola."

Aluno 1: "Ahh, verdade! Não tinha pensado nisso."

A quinta e sexta etapas do trabalho não foram realizadas, pois a instituição parceira não obteve recursos financeiros para a contratação de um serviço de hospedagem do software. Como não encontramos um serviço gratuito de hospedagem, mesmo para fins educacionais, que disponibilize a infraestrutura necessária para as 
tecnologias empregadas no desenvolvimento do software, torna-se necessária a locação de um provedor de serviços de Internet. Neste sentido, a grande frustração da equipe foi a impossibilidade de implantar a aplicação e torná-la disponível online através da Internet. Após a conclusão do software o mesmo foi implantando em um servidor local. O que torna o mesmo acessível à comunidade, mas somente a partir de computadores da rede interna da instituição.

\section{Considerações finais}

Portanto, compreendemos que a proposta inicial de proporcionar uma oportunidade de ampliar o espaço de aprendizagem do estudante, não nos limitando somente aos planejamentos previstos nos componentes curriculares do curso, foi plenamente atingida. Isso pode ser constatado através do relato onde descrevemos o envolvimento dos estudantes em todas as fases propostas no projeto. Os benefícios de uma prática de desenvolvimento de software, orientada por uma equipe interdisciplinar de professores de um curso de tecnologia, pode gerar efeitos positivos no desenvolvimento da aprendizagem dos estudantes. A definição e execução de um trabalho interdisciplinar amplia a compreensão e uma visão macro do processo de desenvolvimento de software. O que, muitas vezes, não é possível quando trabalhamos os componentes curriculares de forma isolada. Sem que ocorra uma inter-relação entre os conteúdos abordados nas disciplinas de um curso.

Outro aspecto observado que permite uma reflexão é a interação constante dos estudantes com tecnologias empregadas no mundo do trabalho. Principalmente, tecnologias que os estudantes abordam durante seus estudos no curso e que são amplamente empregadas na construção de software. Tal aspecto nos deixa muito satisfeitos com o trabalho desenvolvido pelo corpo docente do nosso campus. Visto que tanto conceitos como as abordagens práticas, ferramentas e metodologias empregadas no ensino dos componentes curriculares, estão alinhados ao que o mundo do trabalho demanda.

Cabe destacar, que a proposta evidenciou aos estudantes a importância do desenvolvimento de um trabalho em equipe multidisciplinar. As relações humanas e sua importância para o sucesso de qualquer tipo de empreendimento. O desenvolvimento de maturidade dos estudantes ao longo do processo foi marcante. Muita aprendizagem foi desenvolvida no âmbito das relações profissionais e humanas ao longo do processo.

Para finalizar, gostaríamos de sugerir alguns desdobramentos possíveis da prática educativa apresentada neste artigo. Um primeiro trabalho futuro seria a ampliação do projeto para atender outras demandas da instituição parceira, tal como a elaboração de um sistema de controle acadêmico com mais funcionalidades. Outro desdobramento possível seria a apresentação de um novo projeto que busque recursos financeiros para que a aplicação possa ser implantada em um serviço de hospedagem. Com isso, seria viável criar novas possibilidades de ampliação de espaços de aprendizagem. Onde docentes, estudantes e servidores da escola poderiam trabalhar de forma colaborativa e construir seus próprios recursos educacionais.

\section{Referências bibliográficas}

CARDOSO, R.; ANTONELLO, S. Interdisciplinaridade, programação visual e robótica 
educacional: relato de experiência sobre o ensino inicial de programação. In: Anais dos Workshops do Congresso Brasileiro de Informática na Educação, 2015.

CORDENONZI, W.; CARDOSO, V. M.; LUZ, H.; AMARAL, E. Uma Experiência Interdisciplinar no Ensino de Algoritmos e Matemática em um Contexto Binacional. In: Anais dos Workshops do Congresso Brasileiro de Informática na Educação, 2015.

DEMO, P. Educar pela pesquisa. $8^{\text {a }}$ Edição. São Paulo: Autores associados, 2007.

FRANÇA, R. S.; FERREIRA, V. F. S. ALMEIDA, L. D.; AMARAL, H. D. A disseminação do pensamento computacional na educação básica: lições aprendidas com experiências de licenciandos em computação. In: Anais do XXII Workshop sobre Educação em Computação, 2014.

FREIRE, Paulo. Pedagogia do oprimido. Rio de Janeiro: Paz e Terra, 1987.

GADOTTI, M. Educação e globalização neoliberal: um olhar a partir da América Latina. Revista Educação \& Linguagem, São Paulo, v. 1, p. 62-78, 2009.

LIBÂNEO, J. C. Pedagogia e pedagogos para quê? 12a Edição. São Paulo: Cortez, 2010.

LOPES, A. C; MACEDO, E. Teorias de currículo. 1ª Edição. São Paulo: Cortez, 2013.

LUCK, H. Pedagogia da interdisciplinaridade: fundamentos e referências bibliográficas teórico-metodológicos. Petrópolis: Vozes, 2001.

MOURA, D. H. A formação de docentes para educação profissional e tecnológica. Revista Brasileira da Educação Profissional e Tecnológica, v. 1, n. 1, Brasília, 2008 .

OLIVEIRA, C. D. C.; CINTRA, M. E.; NETO, F. M. M. Jogo sério para o ensino da Gestão de Riscos em Projetos de Softwares usando Inteligência Artificial. Revista Novas Tecnologias na Educação, v. 11, n. 1, 2013.

PACHECO, E. Os Institutos Federais: uma revolução na educação profissional e tecnológica. Brasília: MEC/SETEC, 2010.

SACRISTÁN, J. G. Saberes e incertezas sobre o currículo. São Paulo: Penso, 2013.

SAMPIERI, R. H.; CALLADO, C. F.; LUCIO, M. P. B. Metodologia de Pesquisa. $5^{\text {a }}$ Edição. Porto Alegre: Penso, 2013.

SOUZA, F. N.; Moreira, A. Perfis de questionamento em contextos de aprendizagem online. IE Comunicaciones: Revista Iberoamericana de Informática Educativa, n. 12, p. 15-25, 2010.

THIESEN, J. S. A interdisciplinaridade como um movimento articulador no processo ensino-aprendizagem. Revista brasileira de educação, v. 13, n. 39, p. 545, 2008.

TRIPP, D. Pesquisa-ação: uma introdução metodológica. Revista Brasileira de Educação e Pesquisa, v. 31, n. 3, p. 443, 2005. 